\title{
CONDIÇÕES DE SOBREVIVÊNCIA EM LABORATÓRIO DE HAEMAGOGUS JANTHINOMYS DYAR, 1921 (DIPTERA: CULICIDAE)
}

\author{
Bernard Mondet
}

\begin{abstract}
Neste trabalho, é proposta uma modificação do tubo de Borel, habitualmente utilizado no laboratório para a criação individual de fêmeas de mosquitos. Os primeiros estudos foram realizados com o principal vetor da febre amarela no Brasil, Haemagogus janthinomys. Os resultados, comparados aos da literatura, mostraram um aumento do período de vida das fêmeas, que chegou a 72 dias, uma elevação do número de ovos, até 80, e um ciclo trofogônico mais curto, 7-8 dias. Estes resultados mostram boas perspectivas para estudos posteriores em laborattório sobre a transmissão vertical do virus da febre amarela por este vetor.
\end{abstract}

Palavras-chaves: Criação. Ciclo trofogônico. Fecundidade. Haemagogus. Vetor da febre amarela. Brasil.

A criação em laboratório de fêmeas de mosquitos tem interesse inegável para os estudos sobre fecundidade, duração do ciclo trofogônico, transmissão de vírus e outros agentes patogênicos. A criação individual é indispensável para os estudos sobre taxonomia e variações morfológicas dos descendentes de uma mesma fêmea. Numerosas espécies de culicídeos "de ocos de árvores" se criam em laboratório. Dentro do gênero Haemagogus temos $\mathrm{Hg}$. equinus ${ }^{11}$, Hg. splendens $(=\mathrm{Hg}$.

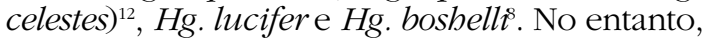
a criação com reprodução, em gaiolas, de machos e fêmeas de $\mathrm{Hg}$. janthinomys, o principal vetor silvestre da febre amarela na América do Sul$^{2}$ é impossível, pois os adultos recusam-se a copular qualquer que seja o tamanho das gaiolas ${ }^{8}$. Vários autores também consideram a sobrevivência dos mosquitos muito difícil ${ }^{139}$.

\section{MATERIAL E MÉTODOS}

Alguns trabalhos com Anopheles demonstraram que, quando se isola fêmeas dentro de tubos individuais, obtêm-se melhores resultados.

\footnotetext{
Laboratório de Entomologia, Serviço de Arbovírus, Instituto Evandro Chagas, Belém, PA, Brasil.

Suporte financeiro: Institut français de recherche scientifique pour le développement en coopération (ORSTOM), Paris, França e Instituto Evandro Chagas (IEC) Belém, PA.

Endereco para correspondência: Dr. Bernard Mondet. Laboratório de Arbovírus/IEC, Caixa Postal 1128, 66090-970 Belém, PA, Brasil. Telefax: (091) 226-5262.

Recebido para publicação em 22/01/96.
}

Bates e Roca-Garcia ${ }^{4}$ adaptaram esta técnica ao Hg. capricornii (= Hg. janthinomys). Cada fêmea, uma vez ingurgitada, era isolada dentro de um tubo de vidro de fundo plano de $25 \mathrm{~mm}$ de diâmetro e $50 \mathrm{~mm}$ de altura. Uma porção de algodão umedecido, e coberto com filtro de papel, era colocado no fundo do vidro para que as fêmeas depositassem seus ovos. Para fechar o tubo na parte superior, era utilizada uma tela de alumínio e sobre esta, um pedaço de algodão umedecido com solução de glicose. Esta técnica é utilizada para a maioria dos experimentos com todas as espécies de culicídeos. Seu principal incoveniente é que as fêmeas se estressam rapidamente e também correm o risco de morrer prematuramente quando colam as asas ou o corpo ao filtro de papel.

Fizemos uma modificação (Figura 1) que consistiu na colagem de um tubo horizontal numa abertura a cerca de $2 / 3$ da altura do tubo vertical. Os dois tubos são de material plástico; o vertical mede cerca de $5,5 \mathrm{~cm}$ de diâmetro e $8 \mathrm{~cm}$ de altura e o horizontal, 3 por $6 \mathrm{~cm}$. O tubo vertical é fechado na porção superior com filó e internamente é revestido por papel de filtro Melitta ${ }^{\circledR}$. Esse tipo de papel, resistente quando úmido, oferece melhor substrato para a fêmea fixar os ovos. Um plástico preto, removivel, é colocado externamente para obscurecer o interior do tubo. Dentro deste tubo é acrescentada a água destilada até cerca de $1,5 \mathrm{~cm}$ de altura. $\mathrm{O}$ tubo horizontal tem sua abertura também protegida por filó e possui uma fenda que, através de uma peça de papelão, permite isolar a fêmea. 
Mondet B. Condições de sobrevivência em laboratório de Haemagogus janthinomys dyar, 1921 (Diptera: culicidae). Revista da Sociedade Brasileira de Medicina Tropical 30:11-14, jan-fev, 1997.

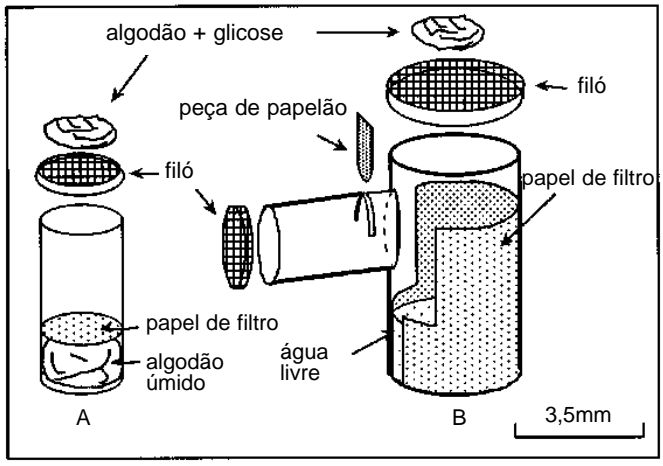

Figura 1 - Esquema dos tubos utilizados para sobrevivência das fêmeas de Haemagogus janthinomys: A: de Borel, B: modificado.

Sobre o tubo principal é colocado um pedaço de algodão umedecido com glicose (Figura 1).

As fêmeas geralmente repousam dentro do tubo horizontal, utilizando o tubo principal somente para postura e alimentação. A contagem dos ovos é feita retirando-se o plástico exterior, já que os ovos permitem ser observados através da transparência do tubo.

Dentro de nossas primeiras experiências, foram utilizadas 22 fêmeas capturadas em natureza, ingurgitadas sobre voluntários vacinados e levadas no mesmo dia ao laboratório. Foram somente utilizadas fêmeas em perfeito estado. As que sofreram qualquer lesão durante a captura ou transporte foram eliminadas. As fêmeas foram acondicionadas individualmente nos tubos duplos. Após cada postura, eram retirados os filtros de papel onde estavam fixados os ovos. A água também era mudada e tentava-se novamente ingurgitar as mesmas fêmeas através do filó que fechava o tubo principal. Caso a postura ainda não houvesse terminado, as fêmeas recusavam o repasto e uma nova tentativa de ingurgitamento era feita no dia seguinte. Durante o curso das experiências, a temperatura da sala de criação ficava entre 24 e $25^{\circ} \mathrm{C}$ e a umidade relativa entre 80 e $85 \%$.

O ciclo trofogônico se compõe de fases com durações variáveis diretamente ligadas às condições externas (temperatura, umidade, abundância de hospedeiros, tipo de vegetação, etc). O ciclo se inicia com o repasto sanguíneo $\mathrm{e}$ as fases seguintes representam a maturação dos ovócitos, a procura de um criadouro, a postura e, enfim, a procura de um novo hospedeiro para realizar outro repasto. No início das estações chuvosas pode haver uma escassez de criadouros naturais com água, o que obriga as fêmeas a uma longa procura. Em laboratório, o tempo dispensado à procura de um lugar para realizar a postura e de um hospedeiro é reduzido ao máximo.

\section{RESULTADOS}

A maturação dos ovos. A maturação dos ovos se inicia a partir do momento que ocorreu o repasto sanguíneo e finaliza com o início da postura. Observou-se que os ovos são postos isoladamente ou em grupos de 2 a 4 sobre o papel filtro e acima da superfície da água. As fêmeas mortas após as posturas eram dissecadas e mostraram poucas relíquias de absorção $^{10}$. Desta maneira, quase não houve $\mathrm{O}$ fenômeno de retenção de ovos com este tipo de tubo de criação. Uma postura correspondeu ao número de ovaríolos que estavam desenvolvidos e a quantidade de ovos pareceu ter uma relação com o volume de sangue ingerido pela fêmea.

A postura. De um total de 22 fêmeas, 10 delas realizaram somente um ciclo, com um total de 322 ovos (média de 32,2 ovos por fêmea). Seis fêmeas realizaram dois ciclos, com um total de 469 ovos (média de 39,1 ovos por postura), 4 fêmeas realizaram 3 ciclos, com um total de 401 ovos (média de 25 ovos). Uma fêmea sobreviveu o tempo suficiente para realizar 6 ciclos, onde foi observado um total de 334 ovos (média de 55,7 ovos). Somente uma fêmea realizou 7 posturas com um total de 171 ovos (média de 24,4 ovos). O número de ovos a cada postura variou entre 5 e 80 . O total observado ao final de 47 ciclos foi de 1724 ovos, com a média de 36,7 ovos por ciclo.

O ciclo trofogônico. As posturas se iniciaram entre o quarto e sexto dia em 41 dos 44 ciclos obtidos, sendo que destes, 24 (57\%) se iniciaram no quinto dia. As posturas foram de 1 a 10 dias, porém 66\% delas ocorreram em 3 dias. Algumas fêmeas aceitaram um segundo repasto sanguíneo no sétimo dia, após o primeiro. Este período foi o mais curto registrado para um ciclo trofogônico.

A sobrevivência. O tempo de sobrevivência das fêmeas foi registrado a partir do dia de captura, o que corresponde ao dia do repasto. De um total de 22 fêmeas que ovipuseram pelo menos uma vez, 10 realizaram um ciclo 
Mondet B. Condições de sobrevivência em laboratório de Haemagogus janthinomys dyar, 1921 (Diptera: culicidae). Revista da Sociedade Brasileira de Medicina Tropical 30:11-14, jan-fev, 1997.

(tempo médio de sobrevivência de 7,4 dias), 6 realizaram dois ciclos (tempo médio de 20 dias) e 4 realizaram 3 ciclos (tempo médio de 30 dias). Uma fêmea realizou 6 ciclos em 52 dias e uma outra realizou 7 ciclos em 72 dias.

A partir desses resultados, foi traçada a curva de sobrevivência das fêmeas (Figura 2).

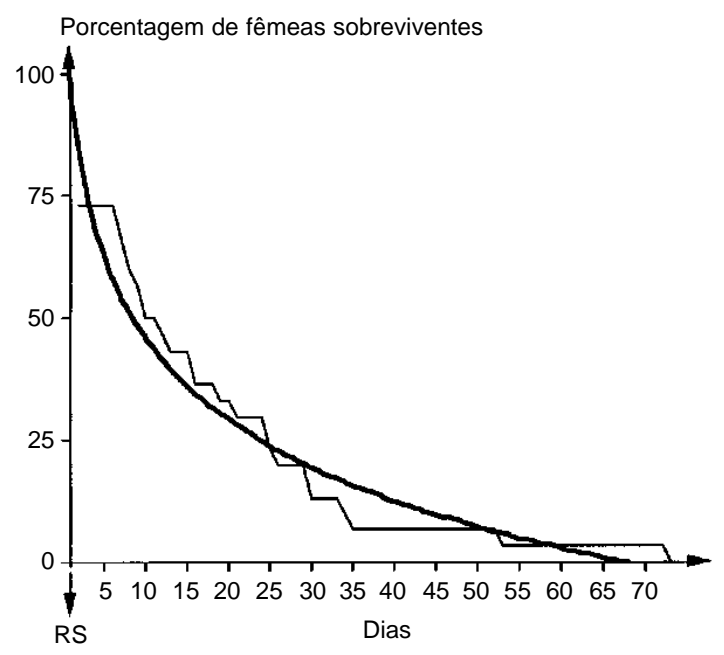

Figura 2 - Curva de sobrevivência, estabelecida a partir da longevidade dentro de tubos duplos, de 22 fémeas de Haemagogus janthinomys, capturadas em natureza e ingorgitadas no laboratório. T: $24-25^{\circ} \mathrm{C}$, UR: $80-85 \%$; RS: repasto sanguíneo.

\section{DISCUSSÃO}

As publicações a respeito de criação de Haemagogus janthinomys são raras. Hovanitz foi o único a ter obtido resultados satisfatórios com sobrevivência dentro de pequenas gaiolas. Obteve um total de 4622 ovos de 165 fêmeas, sendo a média 28 ovos por fêmea. Porém, depois que Bates e Roca-Garcia ${ }^{4}$ demonstraram a superioridade dos tubos individuais para a sobrevivência das fêmeas, as gaiolas não mais foram utilizadas. Bates ${ }^{3}$ estabeleceu uma comparação a diferentes temperaturas. A $30^{\circ} \mathrm{C}$, as fêmeas puseram em média 22 ovos e iniciaram a postura cerca de 6,2 dias após o repasto sanguíneo e sobreviveram 13,8 dias. A $25^{\circ} \mathrm{C}$ as fêmeas puseram cerca de 21 ovos e iniciaram a postura 7,2 dias após o repasto com duração de vida de 18,3 dias. Galindo e cols $^{6}$ obtiveram a postura de 45 fêmeas das 66 que mantinham em laboratório, com um total de 435 ovos, sendo a média menor que 10 ovos por fêmea. O tempo transcorrido entre o repasto de sangue e a postura não foi registrado. Hervé e cols ${ }^{7}$ obtiveram a postura de 125 fêmeas das 268 mantidas em laboratório, porém o número de ovos não foi determinado. A primeira ocorreu entre o quarto e o vigésimo quinto dia após o repasto sanguíneo. Um máximo (66\%) de fêmeas começou a postura entre o sexto e o décimo dia. O tempo médio entre o repasto e os primeiros ovos foi de 8 dias, mas a duração total de cada oviposição não foi precisa.

Assim, comparando-se os nossos resultados com os de estudos similares, que utilizaram tubos simples, observou-se neste estudo que a duração de vida das fêmeas em laboratório aumentou, houve um encurtamento do período compreendido entre o repasto de sangue e a primeira postura, houve também um aumento da quantidade de ovos a cada postura e uma redução dos períodos de posturas.

Estes resultados nos permitem antever a realização de estudos sobre a transmissão vertical de certos arbovírus, como por exemplo o da febre amarela, por fêmeas de Haemagogus. Este tipo de transmissão ainda não foi realizado até o momento, a não ser em fêmeas de $H g$. equinus.

\section{SUMMARY}

A little modification was made on the classical Borel tube, used for rearing isolated females of mosquitoes. The first studies were realized with the main Yellow fever vector, Haemagogus janthinomys, in Brazil. The results are: a better survival, as far as 72 days, a greater number of eggs, up to 80, and a shorter trophogonic cycle of 7-8 days. So, one can imagine more easily further studies about the vertical transmission of the YF virus by this important neo-tropical mosquito.

Key-words: Survival in laboratory. Trophogonic cycle. Haemagogus. Yellow fever vectors. Brazil.

\section{AGRADECIMENTOS}

Agradeço ao Sr. Orlando Vaz da Silva pela confecção dos tubos e particularmente a Srt ${ }^{\underline{\underline{a}}}$ Nelma Freitas pela tradução.

\section{REFERÊNCIAS BIBLIOGRÁFICAS}

1. Antunes PCA, Whitman L. Studies on the capacity of mosquitoes of the genus Haemagogus to 
Mondet B. Condições de sobrevivência em laboratório de Haemagogus janthinomys dyar, 1921 (Diptera: culicidae). Revista da Sociedade Brasileira de Medicina Tropical 30:11-14, jan-fev, 1997.

transmit Yellow Fever. The American Journal of Tropical Medicine 17:825-831, 1937.

2. Arnell JH. Mosquito studies (Diptera, Culicidae) XXXII.A revision of the genus Haemagogus. Contributions of the American Entomological Institute 10:174, 1973.

3. Bates M.The development and longevity of Haemagogus mosquitoes under laboratory conditions. Annals of the Entomological Society of America 40:1-12, 1947.

4. Bates M, Roca-Garcia M. Laboratory studies of the Saimiri-Haemagogus cycle of jungle yellow fever. The American Journal of Tropical Medicine 25:203-216, 1945.

5. Dutary BE, Leduc JW. Transovarial transmission of yellow fever virus by a silvatic vector, Haemagogus equinus. Transactions of the Royal Society of Tropical Medicine and Hygiene 75:128, 1980.

6. Galindo P, Carpenter SJ,Trapido H. A contribution to the ecology and biology of tree hole breeding mosquitoes of Panama.Annals of the Entomological Society of America 48:158-164, 1955.

7. Hervé JP, Sá Filho GC, Travassos da Rosa APA, Dégallier N. Bioécologie d'Haemagogus (Haemagogus) janthinomys Dyar au Brésil.
Cahiers O.R.S.T.O.M., série Entomologie Médicale et Parasitologie 23:203-208, 1985.

8. Hovanitz W. Comparisons of mating behavior, growth rate, and factors influencing egg-hatching in South American Haemagogus mosquitoes. Physiological Zoology 19:35-53, 1946.

9. Kumm HW, Frobisher M Jr.Attemps to transmit Yellow Fever with certain brazilian mosquitoes (Culicidae) and with bedbugs (Cimex hemipterus). The American Journal of Tropical Medicine 12:349-361, 1932.

10. Mondet B. Application de la méthode de Polovodova à la détermination de l'áge physiologique des Aedes (Diptera, Culicidae) vecteurs de Fièvre jaune. Annales de la Société Entomologique de France (Nouvelle Série) 29:6176, 1993.

11. Orsono-Mesa E. Organizacion de una colonia de Haemagogus equinus Theobald. Caldasia (Bogotá) 3:39-45, 1944.

12. Orsono-Mesa E. Factores de interes referentes a la colonizacion de Haemagogus splendens para experimentos de transmision con virus de fiebre amarilla en el laboratorio. Caldasia (Bogotá) 4:453-463, 1947. 